\title{
REFLECTIONS ON LEARNING MATHEMATICS IN PHYSICS PHENOMENOLOGY AND HISTORICAL CONCEPTUAL STREAMS
}

\author{
Maria Mellone, \\ University of Naples "Federico II", Italy \\ E-mail: maria.mellone@unina.it
}

Raffaele Pisano

Chirples, École Normale Supérieure Paris, France/RCTHS,

University of WB, Czech Republic

E-mail: pisanoraffaele@iol.it

\begin{abstract}
Although several efforts produced by new mathematical education approaches for improving education systems and teaching, yet the results are not sufficient to adsorb the totality of innovations proposed, both in the contents and management. In this sense constructive debates and new ideas were welcomed and appreciated upon new aspects of science education, side new learning and Cognitive Modelling, for our interests. A parallel effort was produced by scientist-epistemologist-historians concerning the history of science and its foundations in science education. Historical foundations represent the most important intellectual part of the science, even if sometimes they were avoided or limited to specialist disciplines such as history of mathematics, history of physics, only. Nevertheless some results, such as the operative concept of mass by Mach, rather the coherence and validity of an algebraic-geometric group in a Euclidean geometry and in non-Euclidean geometry was firstly appointed by epistemological point of view by (e.g.,) Poincaré, etc... Thus, what kind of concrete relationship between science education (mathematics and physics) and history of science (idem) one can discuss correlated with foundations of science? and above all, how this relationship can be appointed? The history and epistemology of science help to understand evolution/involution of mathematical and physical sciences in the interpretationmodelling of a phenomenon and its interpretation-didactic-modelling, and how the interpretation can change for a different use of mathematical: e.g., mathematics à la Cauchy, non-standard analysis, constructive mathematics in physics. Based on previous studies, a discussion concerning mathematics education and history of science is presented. In our paper we will focus on learning modelling to discuss its efficacy and power both from educational point of view and the need of mathematics and physics teachers education. Some case-studies on the relationship between physics and mathematics in the history are presented, as well. Particularly we focus on a possible learning modelling activity within physics phenomenology to create a resonance among the above poles and mathematical modelling cycle to argue its efficacy, power and related with historical foundations of physical, mathematical sciences.
\end{abstract}

Key words: modelling, mathematics, physics, history of foundations, epistemology of science.

\section{Introduction}

Nowadays the aims stated in curriculum documents from range of countries reveals an increasing importance given to the role of mathematics in enabling learners to relate to the world beyond the classroom. This idea is also consistent with the definition of mathematical literacy (OECD): Mathematical literacy is an individual's capacity to formulate, employ, 
PROBLEMS

OF EDUCATION

IN THE $21^{\text {st }}$ CENTURY

Volume 46, 2012

94

and interpret mathematics in a variety of contexts. It includes reasoning mathematically and using mathematical concepts, procedures, facts, and tools to describe, explain, and predict phenomena. It assists individuals to recognize the role that mathematics plays in the world and to make the well-founded judgments and decisions needed by constructive, engaged and reflective citizens $(\mathrm{OECD}, 2012)$. This very ambitious goal requests a real innovation of education systems and OECD provides several precious reflections and suggestions for the educational implementation. Among the others the mathematical modelling cycle is the key feature of the recent PISA 2012 framework, the new central stream in the recent theoretical framework. In the earlier frameworks mathematical modelling cycle was used only to describe the stages individuals go through in solving contextualised problems, while in the new document (draft PISA 2012) it is used to define the mathematical processes in which students engage as they solve problems, processes that are being used for the first time in 2012 as a primary reporting dimension. The solve problems process described by the PISA mathematical cycle includes something different from the simple solution of word problems, and if we want to avoid the dangerous to reduce the educational implementation to a PISA test training some different proposal needed. Of course the first ring of the innovation chain is the teacher education. Within mathematics teacher education debate a spectrum of reasonable models are presented. In particular the empirical and theoretical work developed by the research group of Ball and Bass (Ball Thames, \& Phelps 2008; Bass, 2005) starting from the Pedagogical Content Knowledge (PCK, Shulman, 1986), defined Subject Content Knowledge (SKT), by distinguishing in its inner several important categories for the mathematical teaching. A new learning modelling has been proposed: Cognitive Model of Resonance (Guidoni, Iannece \& Tortora, 2005) that describes the interaction among the individuals' natural bent to understand, the official culture and the real world. Thus, a cognitive dynamics model of resonance works in order to catch in particular way the relationship among the Subject Matter Knowledge (physics, mathematics) and Pedagogical Content Knowledge domains. Based on the learning modelling of resonance, we think that modelling activity within physics phenomenology contexts can create a resonance among the individual, the culture and the real world and moreover this kind of activities works consistently with the mathematical modelling cycle proposed in PISA 2012. But to manage this kind of activity in order to drive the introduction of particular cultural formalization the teacher needs another kind of knowledge, indeed Boero and Guala proposed another construct localized into the SKC: the cultural analysis of the mathematical content (CAC). They looked at mathematics as an evolving discipline, with different levels of rigor both at a specific moment in history (according to the cultural environment and specific needs), and across history, and as a domain of culture as a set of interrelated cultural tools and social practices, which can be inherited over generations (Boero \& Guala, 2008) and concerning physics and mathematics general foundations and specific subject matter in particular. The CAC perspective should need deeply studies within an integrate history of science and education, particularly competencies coming from epistemology and history of mathematics. Thus, how is it possible to keep on teaching sciences being unaware of their conceptual origin/streams, cultural reasons and eventual conflicts and values? And how is it possible to teach and comment on the contents and certainties of physics and mathematics as sciences without having first introduced sensible doubt about the inadequacy and fluidity of such sciences in particular contexts? Particularly, how history of science works in pedagogical and subject modelling?

\section{History of Science and Science Education}

Generally speaking, mathematics and physics education proceeded according to a strict assumption that in secondary schools the teaching by principles and a major mechanical amount of exercises only, as well as of mere deductive experiments, are required. In this sense, what 
Maria MELLONE, Raffaele PISANO. Reflections on Learning Mathematics in Physics Phenomenology and Historical Conceptual Streams

is the constitutive character and structure (Nagel, 1961) of science that we teach? Is it the same of the original theories? For example one can see paradox of the formalization of logic (Carnap 1943) where in order to express the axioms and to construct a meta-discourse about them, we should use the natural language, which is not-formalized. We cannot formalize it in advance, because we risk producing a regression to infinitum. Moreover, it is not spontaneous for a human to state the axioms of logics and then to consequently deduce all the rest from them (Ibidem). In fact, in everyday life that is never done. When we speak, we usually proceed from temporary premises, and then introduce or remove logical elements of natural language. That is a natural linguistic inference, which can express both classical and non-classical logics (Prawitz \& Melmnaas 1968). In mathematical-classical logic, so-called well-formed-statements are assumed to be either true or false, even if we do not have a proof of either. In fact, from an inferential and classical logic system (e.g. a list of inferential propositions) one can only obtain a scientific dichotomy of hypothesis-these free-from-self-contradiction and among them, and a theory to be scientific must be testable, e.g., subject to falsification (Popper 1963). Let us note that in that kind of system of reasoning ${ }^{1}$, it is not possible to obtain undecidable contents, e.g. like (apparently) those generated by scientific statements belong to non classical logics. Particularly, if undecidable contents belong to a given principle of the theory, then we have an out of the ordinary principle. One may see Euclidean geometry and its relationship with continuum in mathematics in the history (Szczeciniarz 2005). An ideal images, a body (e.g., polygon) is the result of a process of idealization of reality, naturally elaborated by our mind. The empirical performance in geometry, as Poincaré (1854-1912) thought in the La Science et la Hypothèse, represents but the occasional stimulus required to make the image materialize (Pisano 2006). In fact, wondering whether the metrics system is true and the old measurement system is false, is nonsense since it is not possible to choose one type of geometry rather than another, because there is no such thing as a better geometrical group. Thus, what is the cultural gap between imaged science and practical education science? Let us think, e.g., about the lack of a relationship between physics and logic (Pisano \& Gaudiello, 2010), the organization of a scientific theory and its pedagogical aspect based on planned and calculated processes. Through an intelligent use of pedagogical computing technologies, a kind of teaching might be accomplished with the model of the prevailing method of the teaching-learning process mainly related to modelling activities of phenomenology contexts within different paths of history of science: the statics in Nemore (fl. XIII century) and in Tartaglia ${ }^{2}$ (c.1500-1557), physics-chemistry by Newton and by Lavoisier (1743-1794), Galileo's (1564-1642) mechanics (Pisano 2009a; 2009b), Newton's (1642-1727) mechanics, L. Carnot's (1753-1823) mechanics (Gillispie \& Pisano 2012), historical foundations of thermodynamics and thermodynamics in the textbooks (Pisano, 2010; 2011b). The history and epistemology of science (mathematics, physics) can be part of a complex cultural modelling proposing evolution/involution of mathematical and physical sciences in the interpretation-modelling of a phenomenon and its interpretation-didactic-modelling? And how the interpretation can change for a different use of mathematical?

\section{A Cognitive Model and its Educational Spin-off}

In our opinion every teacher's action, both in the plan and the practice of a learning path, is necessary to refer to a model of cognitive dynamics, natural and forced by teaching mediation, but this reference is often unconscious for the teacher. As we state in the introduction the particular learning model we are presenting works in order to catch the relationship among the Subject Matter Knowledge and Pedagogical Content Knowledge domains in the Ball and Bass's model and frames the specific role of the history and epistemology of science from the educational point of view. The Cognitive Model of Resonance is based on the idea of resonance 
PROBLEMS

OF EDUCATION

IN THE $21^{\text {st }}$ CENTURY

Volume 46, 2012

96

dynamics as a root of the learning process (Guidoni, Iannece \& Tortora, 2005; Mellone, 2008; Iannece \& Tortora, 2008). It originally belonged to phenomenological framework and has recently been validated by research findings in the field of neuroscience. The concept of resonance is the main idea: metaphorically evoked to describe the basic structure of the interaction between an individual and the surrounding environment. People produce and use a variety of mental models and hypotheses that they continually compare with the reality as perceived through the senses and communication. In other words, the mind of each individual is constantly exploring the possibilities of resonance between an internal cognitive simulation and an external perceptive and cultural input. Through this process of trial and error, reinforcing successes, and removed errors, all humans construct and stabilize mental models that constantly change and evolve. This kind of model plays for explaining cognitive processes supported by neurological model proposed by Changeux to account for the structural functioning of the brain: the learning process stems from a biological aptitude to continuously produce pre-representations by means of temporary synapses, which can become stable or dissolve depending on a comparison with the external reality (Changeux, 2002). Since the resonance modelling between individual cognition and world is not enough for the learning of physics and mathematics, the individual's hypotheses and pre-representations are also constantly confronted with the cultural systematization of the discipline and the social community with which that individual interacts while developing her/his own knowledge. Within socio-cultural approach (Vygotskij, 1978), the resonance between individual cognition and cultural context acts as a dynamic background and support for the development of any kind of knowledge, both local (in terms of time and contexts) and non-local (long-term and context-free, i.e. abstract). This model for cognitive processes also outlines a way of looking at learning which allows correlating conceptual understanding with the motivation to understand: any experience of actual resonance is directly connected with the sphere of emotions (and of choices), which produces an immediate feedback in terms of validation and reinforcing: "[...] there are $[\ldots]$ a world outside (always the same) working in its own way within a non stop interaction with [...] a world inside (new for each born) trying to understand by mediation of [...] a world of interface (in constant evolution) named "culture". (Guidoni, 2008, p. 3). The teacher's careful planning should aim to choose suitable contexts and tasks that would allow the students to experience the resonance between their cognitive needs and the tools that their cultural context lend to them: how to enhance their ability to mediate among the individuals' natural bent to understand the gap in-between culture-foundations and the world in order to recognize pupils' resources/strategies? And foundations and mathematical physical conceptions in order to let pupils' common knowledge resonate with scientific thought? Let us think about the historical and educational problems on infinitesimal entity in limits operations both mathematics and physics. Thus a re-invention of mathematics based on physical phenomenology and knowledge accessible to pupils is necessary: a re-construction of mathematical meanings, in ways as mathematically stimulating as possible, but assuming only language, knowledge, and skill as primitive as what is usually available to pupils (Freudenthal, 1973).

\section{Physical and Mathematical Laws in the History}

It is note that a physical laws establish a mathematical-physical relationship among numerical-data and physical magnitudes. One of the laws of the German physicist George Simon Ohm (1787-1854), we can currently state: $V=R I$. That is, $V$ is equal to the resistance $R$ multiplied by the current $I$. In physics, we know that the scientific validity of an affirmation depends on the physical system, the adopted theoretical-experimental model and the theory's field of applicability. $V=R I$, belonging to physics, expresses a particular logical action according to which (I, see below) the truth of a conjunction (compared to given model ${ }^{3}$ ) would 
Maria MELLONE, Raffaele PISANO. Reflections on Learning Mathematics in Physics Phenomenology and Historical Conceptual Streams

imply the truth of both members in $V=R I$; while the opposite would not be logically applicable. Moreover, general speaking, the (II, see below) non-truth of a given proposition does not imply the truth of its negation. It means that, given two quantities $A$ and $B$, one can write the following two logical state@ent: (I): $(A \quad B)$ true $\odot A$ true, $B$ true. Thus, $A$ true, $B$ true $\neq(A$ @ $B)$ true; (II): $\neg(\mathrm{A}) \neq \neg \neg$ (A). In other words, this result would weakly violate the validity of the principle of Tertium non datur. ${ }^{4}$ Thus, what does it mean measure by $V=R I$ ? As a matter of fact, by considering up above discussion, in order to measure Ohm's law a simultaneous measurement of the three quantities $V, R, I$, should be required. In this sense, in order for (1) to be experimentally true, it is necessary for three real corresponding numbers $a, b, c$, should exist respectively for the measurements of $V, R$, and $I$. Thus, one can write $a=b c$. The measurement is obviously never perfect (experimental data should coincide with the theoretical ones only within limits of the experimental errors). Therefore, because of the uncertainties of the devices and error of measurement, in the same range of measurement of $a, b, c$, it should exist another real triad $a^{\prime}, b^{\prime}, c^{\prime}$ with $\left(a^{\prime} \neq a\right),\left(b^{\prime} \neq b\right),\left(c^{\prime} \neq c\right)$, should exist, so that: $a^{\prime} \neq b^{\prime} c^{\prime}$. Both $a=b c$ and its negation $a^{\prime} \neq b^{\prime} c^{\prime}$ would be true with respect to a given experimental situation. The conjunction of $a=b c$ and $a^{\prime} \neq b^{\prime} c^{\prime}$ would not be true, because it should exits a real triad $a, b, c$ so that one simultaneously should obtain: $a=b c$ () a $a$ bc which in classical logics is false. ${ }^{5}$ In the end, every physical variables should be subjected to its measurement; if not, the scientific content generates uncertainties in scientific knowledge. These aspects plays have an important role in science education during, e.g. the shift from laboratory and theoretical lessons.

\section{Final Remarks}

From cognitive-epistemological point of view (George \& Velleman, 2002), people do not naturally reason by means of deductive/ inductive processes only. In this regard, scientific reasoning (Lakoff \& Nunez, 2000) is not a part of our common knowledge, although we often intuitively compare events, tables etc. Instead, is we consider reasoning such as associations of ideas within resonance dynamics, some concepts are far from the scientific ones and need to put in resonance with them on dialectic between of scientific and everyday concepts (Vygotskij). E.g., heat and temperature, mass, weight and force-weights, the solar system and atomic orbital system in quantum mechanics, the kinetic model of gases and thermodynamics, parallel straight, material points. An hypothetical proposal, of course not the only one possible, could be the introduction within the educational plan of reading passages ad hoc centred on mathematics and physics to be analysed in the classroom main books ${ }^{6}$ by Aristotle's mechanics (mechanical problems), Euclid(Elements), Archimedes (On equilibrium of planes), Tartaglia (Quesiti), Galilei (Discorsi), Torricelli (Opera), Lazare Carnot (Essai) Lavoiser (Traité) Sadi Carnot (Réflexions), Faraday (Experimental Researches) etc. Reading such passages, together with pre-arranged and effective work shared by several subjects, 1) the student is placed before a problematic situation and driven to realise the inadequacy of his/her basic knowledge with regard to problem solving. 2) When the build up of scientific education begins, in order to overcome such difficulties. The result will be pedagogy according to which science education (Osborne \& Collins, 2003; Debru 1997) essentially means setting and solving problems and teaching means re-evaluating the between theory and experience and between history and foundations. They could come together with well-structured and practical interdisciplinary work by means of the history of science. As up above discussed the gap between mathematics/physics teaching and mathematics/ physics such as theories is crucial both for teachers and pupils. The interdisciplinary is in philosophy, epistemology, logic and the foundations of physical and mathematical sciences. Thus, the capacity of mathematics to comprise information in abstract-form (Packing) useful to create theory models and interpretation of physical (Interpretation) phenomena is a general disciplinary model. While maths teaching needs a decompression (Unpacking) to explicit 
PROBLEMS

OF EDUCATION

IN THE $21^{\text {st }}$ CENTURY

Volume 46, 2012

98

and re-organize its foundations (Bass, 2005). Nowadays mathematics teacher educators are mostly interested in developing teachers' competencies related to pedagogical aspect of the knowledge, and also their preparation is oriented in the same direction: "Mathematicians who engage in teacher education do not seem interested in the CAC perspective, and their scientific career as mathematicians does not depend on CAC competencies. The CAC perspective needs competencies coming from epistemology of mathematics, history of mathematics, and philosophy of mathematics" (Boero \& Guala, 2008, p. 242). Moreover, we think that it is not necessary generalize disciplines; it could be - at first step - sufficient to think to re-focus on historical/interdisciplinary cognitive objectives. It could be interesting to build the capacity of abstraction in pupils by means of multi-values logics. Thus, according to the Cognitive Model of Resonance the teacher's careful planning should aim to choose suitable contexts and tasks that would allow the students to experience the resonance between their cognitive needs and the tools that their cultural context lend to them. Thus at school, science education need a strong effort for an interdisciplinary approach to teach and learn the relationship physics-mathematics (Pisano 2011a) as a discipline of study (Martinez; Meltzoff, Huhl, Movellan \& Sejnowski, 2009). Education needs to revaluate scientific reasoning as an integral part of human (humanistic and scientific mixed) culture that could build up an autonomous scientific cultural trend in schools. In this sense, what about the importance of introducing the history of science as an integral part of the culture of teaching education to the extent of considering such a discipline - in its turn - as an indissoluble pedagogical element of history and culture? "To foresee the future of mathematics, the true method is to study its history and present state" (Klein 1980, p. 3). It would be useful to pay particular attention to the elaboration of the teaching-learning process and modelling based on the reality observed by students (inductively), by a continuing critical reflection, e.g. by means of studying the historical foundations of modern physical and mathematical sciences. Therefore, turning from teaching based on principles to teaching (also) based on broad and cultural themes would be crucial. In this way, both a student is the protagonist, and schools training experts teacher (teach, work and publish) to provide a setting on teaching research aimed at the critical re-construction of scientific meanings along with ideas and contents.

\section{References}

Ball, D. L., Thames, M. H., \& Phelps, G. (2008). Content knowledge for teaching: What makes it special? Journal of Teacher Education, 59 (5), 389-407.

Bass, H. (2005). Mathematics, mathematicians and mathematics education. Bulletin of the American Mathematical Society, 42 (4), 417-430.

Boero, P., \& Guala, E. (2008). Development of mathematical knowledge and beliefs of teachers. In: Sullivan P., \& Wood, T. (Eds.), The International Handbook of Mathematics Teacher Education. Purdue University, USA: Sense Publishers, Vol. 1, p. 223-244.

Boero, P., Pedemonte, B., \& Robotti, E. (1997). Approaching Theoretical Knowledge Through Voices and Echoes: a Vygotskian Perspective. In: Proceedings of the $21^{\text {th }}$ Conference of the International Group for the Psychology of Mathematical Education, Pehkonen E. (Ed.), Vol. 2, Lahti: Research and Training Center. University of Helsinki, p. 81-88.

Capecchi, D., \& Pisano, R. (2010). Reflections on Torricelli's principle in mechanics. Organon, 42, 8198.

Carnap, R. (1943). Formalisation of Logic, Cambridge MA: The Harvard University Press.

Changeux, J. P. (2002). L'Homme de Vérité. Paris: Éditions Odile Jacob.

Da Costa, N., \& French, S. (2003). Science and Partial Truth: A Unitary Approach to Models and Reasoning in Science. New York: The Oxford University Press. 
Maria MELLONE, Raffaele PISANO. Reflections on Learning Mathematics in Physics Phenomenology and Historical Conceptual Streams

$\mid$\begin{tabular}{l} 
PROBLEMS \\
OF EDUCATION \\
IN THE 21 $1^{\text {st }}$ CENTURY \\
Volume 46, 2012 \\
\hline 99
\end{tabular}

Debru, C. (1997). On the Usefulness of the History of Science for Scientific Education. Notes and Records of the Royal Society of London, 51 (2), 291-307.

Freudenthal, H. (1973). Mathematics as an educational task. Dordrecht, Netherlands: Reidel.

Garuti, R. (1997). A Classroom Discussion and a Historical Dialogue: a Case Study. In: Proceedings of the $21^{\text {th }}$ Conference of the International Group for the Psychology of Mathematical Education, Vol. 2, Lahti: Research and Training Center. University of Helsinki, p. 297-304.

George, A., \& Velleman, D. J. (2002). Philosophies of Mathematics. Oxford: Blackwell

Gillispie, C. C., Pisano, R. (2012). Lazare And Sadi Carnot. A Scientific And Filial Relationship. HMMseries. Dordrecht: Springer.

Guidoni, P. (2008). Il mondo in cui viviamo e il mondo in cui lo vediamo/conosciamo. Retrieved 2008, from http://people.na.infn.it/ santorel/docs/prof/Guidoni.pdf

Guidoni, P., Iannece, D., \& Tortora, R. (2005). Forming teacher as resonance mediator. In: Proceedings of the $2^{\text {th }}$ Conference of the International Group for the Psychology of Mathematical Education, Vol. 3, Chick, H.L. \& Vincent, J.L. (Eds.). Melbourne: University of Melbourne Press, p. 73-80.

Hodges, W. (1983). Elementary Predicate Logic. In: Gabbay, D.M., \& Guenthner, F. (Eds.), Handbook of Philosophical Logic - Elements of Classical Logic. Dordrecht: Reidel, Vol. I, p. 1-131.

Iannece, D., \& Tortora, R. (2008). Resonance: a key word in mathematics teaching-research. In: Czarnocha, B. (Ed.), Handbook of Mathematics Teaching Research: Teaching Experiment - A Tool for Teacher-Researchers Rzeszów: The Rzeszów University Press, p. 59-70.

Klein, M. (1980). Mathematics. The loss of certainty. Oxford: The Oxford University Press.

Kolmogorov, A. N. (1925). On The Principle "Tertium Non Datur”. Matematicheskij Sbornik, Vol. 32, p. 646-667 (Engl. Transl. in Kolmogorov (1991-1993) Selected Works of A. N. Kolmogorov, Tikhomirov V. M. (Ed.). Dordrecht-Boston: Kluwer Academic Publishers, Vol. I, p. 40-68).

Lakoff, G., \& Nunez, R. E. (2000). Where mathematics come from. NY: Basic Books.

Mellone, M. (2011). The influence of theoretical tools on teacher's discipline of noticing and classroom practice: a case study. Journal of Mathematics Teacher Education, 14 (4), 269-284.

Mellone, M. (2008). Un progetto didattico innovativo sulle strutture aritmetiche. $\mathrm{PhD}$ thesis. University of Napoli “Federco II", Naples. Retrieved 2008, from http://www.fedoa.unina.it/2017/1/Mellone Scienze_Matematiche.pdf

Meltzoff, A. N., Kuhl, P. K., Movellan, J., \& Sejnowski T. J. (2009). Foundations for a new science of learning. Science, 325 (5938), 284-288.

Nagel, E. (1961). The Structure of Science. NY: Harcourt-Brace \& World Inc.

Newton, I. (1803). The Mathematical Principles Of Natural Philosophy, by Sir Isaac Newton. Translated into English by Motte, A. London: Symonds, vol. I.

OECD-Organisation for Economic Co-operation and Development (2010). PISA 2012 Mathematics framework. Retrieved 2010, from

http://www.oecd.org/dataoecd/8/38/46961598.pdf

Osborne, J. S, \& Collins, S. (2003). Attitudes towards science: a review of the literature and its implications. International Journal of Science Education, 25 (9), 1049-1079.

Pisano, R. (2011a). Physics-Mathematics Relationship. Historical and Epistemological notes. In: Proceedings of the ESU 6 History And Epistemology In Mathematics Education Barbin, E., Kronfellner, M. \& Tzanakis, C. (Eds.). Vienna: Verlag Holzhausen GmbH-Holzhausen Ltd., p. 457-472.

Pisano, R. (2011b). Textbooks, Foundations, History Of Science and Science education. Problems of Education in the 21st Century, 35, 5-10.

Pisano, R. (2010). On Principles In Sadi Carnot's Theory (1824). Almagest, 2, 128-179.

Pisano, R. (2009a). On method in Galileo Galilei' mechanics. In: Hunger, H. (Ed.), Proceedings of ESHS $3^{\text {rd }}$ Conférence, Vienna: Austrian Academy of Science, p. 147-186. 
PROBLEMS

OF EDUCATION

IN THE $21^{\text {st }}$ CENTURY

Volume 46, 2012

100

Pisano, R. (2009b). Continuity and discontinuity. On method in Leonardo da Vinci' mechanics. Organon, 41, 165-182.

Pisano, R. (2006). La Science et la Hypothèse di J.H. Poincaré. Note epistemologiche. Rivista di Epistemologia Didattica, 1, 279-300.

Pisano, R., \& Gaudiello, I. (2009). Continuity and discontinuity. An epistemological inquiry based on the use of categories in history of science. Organon, 41, 245-265.

Popper, K. (1963). Conjectures and Refutations: The Growth of Scientific Knowledge. London: Routledge.

Prawitz, D., Melmnaas, P. E. (1968). A survey of some connections between classical, intuitionistic and minimal logic, In Schmidt, A., \& Schuette, H. (Eds.), Contributions to Mathematical Logic. Amsterdam: North-Holland Press, p. 215-229.

Skolem, T. ([1920] 1967) Logico-Combinatorial Investigations in the Satisfiability or Provability of Mathematical Propositions, In: Heijenoort, J. van (ed.) From Frege to G\&oumldel: A Source Book in Mathematical Logic, 1879-1931. Cambridge MA: The Harvard University Press, p. 252-263.

Szczeciniarz, J. J. (2005). Philosophie et géométrie: la montée de la géométrie, ses effets philosophiques. In: Géométrie au XXe siècle, 1930-2000. Histoire et horizons, Kouneiher, J. (Ed.) Paris: Hermann, p. 334-350.

Vygotsky, L. S. ([1931] 1978). Mind in society. The development of higher psychological processes. Cambridge, MA: The Harvard University Press.

(Endnotes)

1 On the foundations of science, model and reasoning see Da Costa and French (Da Costa \& French, 2003).

2 Capecchi, D., \& Pisano, R. (forthcoming). Niccolò Tartaglia. The science of weighs in XVI century, Dordrecht: Springer.

3 We only consider situations and models where the magnitudes $\left(\mathrm{S}_{1 \ldots} \mathrm{S}_{\mathrm{n}}\right)$ are physically measurable.

$4 \quad$ On The principle of Tertium non datur see Kolmogorov (Kolmogorov, 1925; see also Hodges 1983).

5 On can also see Newtonian principle of inertia (Newton 1803, I, p. 2, p. 23) where the physical laws can be expressed by means of a proposition preceded by two universal and existential quantifications: $(\forall)$ ("for all") and ( $\exists$ ) ("there exists" or "for some").

6 Previously historical reading on the same intends but with different aims were experimented (Boero 1997; Garuti, 1997).

Advised by Vincentas Lamanauskas, University of Siauliai, Lithuania

Received: May 16, 2012

Accepted: August 20, 2012

\begin{tabular}{|c|c|}
\hline Maria Mellone & $\begin{array}{l}\text { Ph.D., Associate Researcher, Department of Mathematics "Renato Caccioppoli", } \\
\text { University of Naples "Federico Il", Italy. } \\
\text { E-mail: maria.mellone@unina.it }\end{array}$ \\
\hline Raffaele Pisano & $\begin{array}{l}\text { Ph.D., Associate Researcher, Chirples, École Normale Supérieure Paris, } \\
\text { France. } \\
\text { Head of Research Center for Theory and History of Science, University of West } \\
\text { Bohemia, Czech Republic. } \\
\text { E-mail: pisanoraffaele@iol.it }\end{array}$ \\
\hline
\end{tabular}

